\title{
The outcome of the use of llizarov technique in the management of congenital fibular hemimelia: Review of cases admitted to Erbil Teaching Hospital in Kurdistan region of Iraq
}

\section{Abstract}

Background and objective: Patients affected by fibular hemimelia primarily presented clinically as foot deformities and limb length discrepancies. Surgical restoration of normal limb alignment and length has been reached by using llizarov technique. This study aimed to determine the outcome of using Ilizarov procedure in the management of lower limb discrepancy cases in Erbil.

Methods: This study is a review of fibular hemimelia cases managed at the orthopedic department of Erbil Teaching Hospital between November 2014 and June 2018. Fibular hemimelia patients complaining from lower limb shortening of 3-11 cm were included in this study. All patients were examined pre and post application of llizarov procedure to determine the range of lower limb motion by using the lower extremity functional scale. Ilizarov operative technique was used for the correction of deformities and restoration of normal limb length and alignment.

Results: Eight fibular hemimelia patients, including three males, were enrolled in the study with a mean $( \pm S D)$ age of $7.37 \pm 4.13$ years (range from 3 to 16 years). They had a mean limb shortening of $6.06 \pm 2.36 \mathrm{~cm}$. A wide range of residual deformities and congenital anomalies was reported among fibular hemimelia cases. A number of residual deformities and complications were associated with Ilizarov technique affecting the knee joint, proximal tibia, and ankle joint. Improvement in the lower extremity functional scale from quite a bit and moderate difficulty to a little bit of difficulty $(P<0.001)$ between the two means of pre and postoperative lower extremity functional scale was demonstrated.

Conclusion: llizarov procedure is effective in improving the lower extremity function in fibular hemimelia despite the associated complications and leg length inequality.

Keywords: Fibularhemimelia; Foot deformities; Limb length discrepancy; llizarov technique.

\section{Introduction}

Fibular hemimelia $(\mathrm{FH})$ is a congenital condition characterized by the deficiency of part or all of the fibular bone, which is usually associated with a broad spectrum of lower limb congenital anomalies. ${ }^{1}$ Although a chromosomal anomaly has been reported, the causes of the development of $\mathrm{FH}$ are still unclear. ${ }^{2}$ Patients affected by $\mathrm{FH}$ are primarily presented clinically as foot deformities and limb length discrepancies (LLD) ${ }^{1-3}$ The primary aim of treating such a condition is the surgical restoration of normal limb alignment and length with a stable walking on the soles of the feet. ${ }^{4,5}$ This aim has been reached by using llizarov principles in which elongation of $40 \%$ to $70 \%$ of the affected lower limb was possible, although this principle is associated with increased complications. $^{6-9}$ Gavriil Abramovich llizarov first introduced llizarov technique in 1950 for the management of bone lesions caused by tuberculosis. This technique focuses on biologic quality of the regenerated bone in which percutaneous corticotomy minimizes periosteum and bone marrow trauma and maximizes the

${ }^{1}$ Department of General Surgery, College of Medicine, Hawler Medical University, Erbil-I raq.

* Correspondence: zainababdulwahab@yahoo.com 
bone marrow and periosteal blood supply preservation. ${ }^{10}$ This technique undergoes many modifications and advances, although basic principles remain intact. ${ }^{6,11}$ This study aimed to determine the outcome of using llizarov procedure in the management of lower limb length discrepancy cases, including the complications and improvement in lower extremity function among cases admitted to Erbil Teaching Hospital.

\section{Methods}

This study is a review of $\mathrm{FH}$ cases managed at the Orthopedic Department of Erbil Teaching Hospital over 42 months, between November 2014 and June 2018. $\mathrm{FH}$ patients admitted to the orthopedic outpatient clinic of Erbil Teaching Hospital complaining from lower limb shortening of $3-11 \mathrm{~cm}$ with a foot having $\geq 3$ rays were included in this review. Other forms of congenital anomalies associated with the $\mathrm{FH}$ were recorded. The exclusion criteria were $\mathrm{FH}$ patients with general medical status considered unfit for general anesthesia, those with active infection of the hip joint, femur, knee joint, tibia or ankle joint, those with the foot having less than three rays, and those with lower limb shortening greater than $20 \mathrm{~cm}$. All patients were examined pre and post application of Ilizarov procedure to determine the range of lower limb motion by using the lower extremity functional scale (LEFS). This LEFS is a questionnaire containing 20 self-reporting questions regarding the patient's ability to perform daily tasks. It is composed of four functional groups, and each group is rated on a five-point scale (0-4). These groups include extreme difficulty or unable to perform an activity (5-19 points), quite a bit of difficulty (20-39 points), moderate difficulty (40-59 points), a little bit of difficulty (60-79 points), and no difficulty (80 points). ${ }^{12}$ The scale is used by clinicians to measure patients' initial function, condition progression and outcome with a disorder of one or both lower extremities, and to evaluate the effectiveness of an intervention (surgical or medical). ${ }^{13}$ The lower the score, the greater the disability and vice versa, and the greater the difference between pre and post intervention scores indicates the more effectiveness of this intervention. ${ }^{13}$ Regarding the decision of treatment, Birch classification $^{8}$ was adopted depending on the percentage of limb shortening (femur, tibia or both of them) compared to the normal limb and the function of the foot (which was defined as one that was or could be made plantigrade and had three or more rays). Foot and ankle deformities were classified according to Paly classification (Table 1$)^{1}{ }^{1}$

Table 1: Paly classification of foot and ankle deformities.

\begin{tabular}{ll}
\hline Type of deformity & Description \\
\hline Type I & Stable ankle \\
Type II & Dynamic valgus ankle \\
Type III & Fixed equino - valgus anle \\
III A & Ankle type \\
III B & Sub talar type \\
III C & Fixed equino-varus \\
\hline
\end{tabular}


Lower limb length was measured by using a tape measure from anterior superior iliac spine to the medial malleolus of tibia. All patients were sent for an X-ray study (anteroposterior and lateral) and scanogram in the standing position to detect a deviation in the mechanical axis, measuring limb shortening and clarifying associated congenital deformities.

\section{Operative procedures}

Five patients underwent soft tissue release, including elongation of Achilles tendon, posterior capsulotomy of the ankle joint, resection of fibrocartilage anlage of the fibula. In tibial lengthening, llizarov frame was applied with a proximal ring parallel to the knee joint and a distal ring parallel to the ankle joint. A calcaneal ring was attached. Corticotomy was done at the center of rotation of angulation (CORA), usually in the center of the diaphysis of the tibia. Distraction bar was inserted on the concave side, and with distraction, the tibial bowing was corrected after achieving the correction of anterior bowing of the tibia. The distraction and the hinges replaced by three motors to promote lengthening (Figure 1).

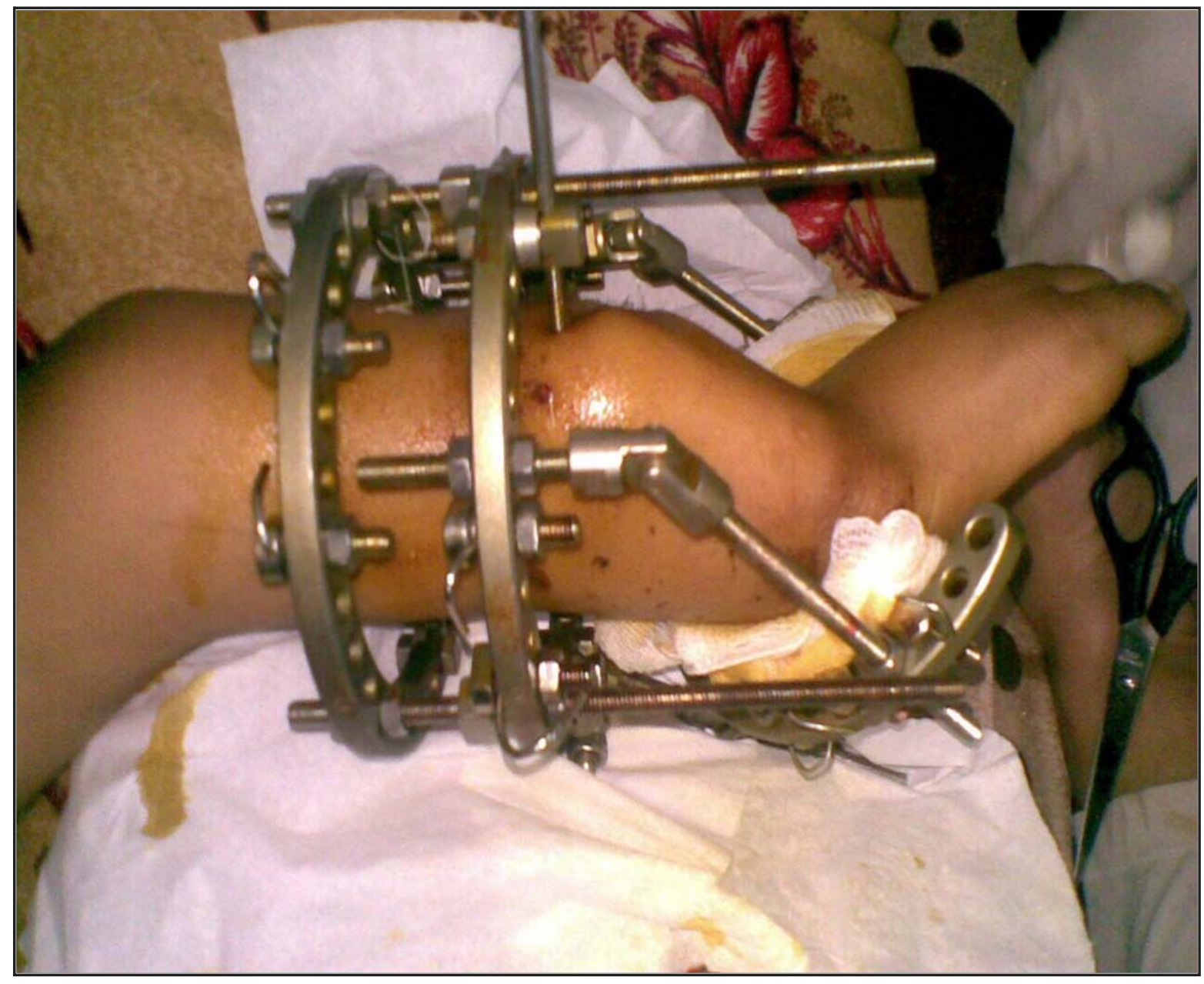

Figure 1: Application of llizarov frame on the tibia. 
The operative technique used is that described by Paley and Pfiel. ${ }^{14}$ For those having associated femoral shaft shortening, femoral lengthening usually was done separately from tibial lengthening. For femoral lengthening and after the Ilizarov frame was applied, the $1^{\text {st }}$ reference wire passed at the level of adductor tubercle or superior pole of patella parallel to knee joint. Preconstructed assembly was applied, and tension was applied to the wires. Two half pins passed anterolaterally at lessor trochanter level and fixed to the superior arch of the device, which was parallel to a line joining the center of the femoral head with the tip of the greater trochanter, and perpendicular to the mechanical axis of the femur. The arch is connected to the middle ring by three rods. The middle ring applied superior to the osteotomy site was held by two tension wires and one pin that passed from lateral to medial direction. The distal ring also reinforced by two tension wires and one pin that passed from posterolateral to the anteromedial direction. Four motors were applied between middle and distal rings, and osteotomy performed through metaphysis and $2 \mathrm{~cm}$ away from the proximal half of the distal ring (Figure 2).

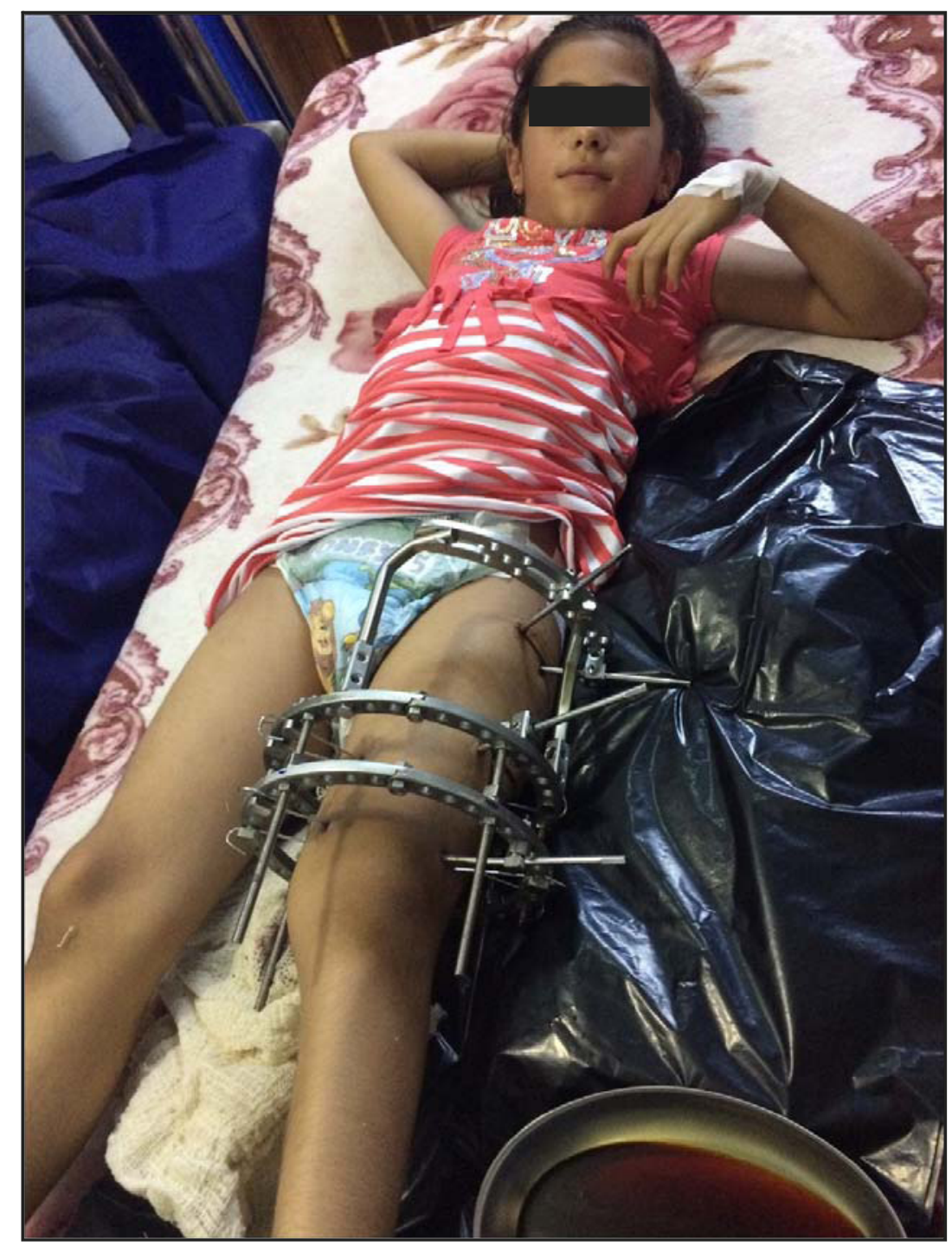

Figure 2: Application of llizarov frame on the femur. 
No amputations were performed on any of the enrolled patients. The study was approved by the research ethics committee of the College of Medicine of Hawler Medical University, and informed consent was obtained from the patient's parents or guardian. A descriptive analysis of data was conducted using excel software. The means and SD of lower extremity functional scores pre and postoperatively were calculated, and paired t-test was used to compare the means. Data were presented in the form of tables. A $P$ value of $\leq 0.05$ was considered statistically significant.

\section{Results}

Eight $\mathrm{FH}$ patients, three males and five females, were enrolled in this study with a mean $( \pm S D)$ age of $7.37 \pm 4.13$ years (range from 3 to 16 years). In three of these patients, the left lower limb was affected. A family history of $\mathrm{FH}$ was reported by $12.5 \%$ of patients (Table 2 ).

Table 2: Discriptive criteria of fibular hemimelia cases included in the study.

\begin{tabular}{lcc}
\hline Variable & No. & $\%$ \\
\hline Age (mean = 7.8 \pm 4.5 years) & 4 & 50.0 \\
$\leq 7$ years & 4 & 50.0 \\
$>7$ years & & \\
Gender & 3 & 37.5 \\
Male & 5 & 62.5 \\
Female & & \\
Lower limb affected & & 62.5 \\
Right & 5 & 37.5 \\
Left & 3 & 100.0 \\
Family history of FH & & \\
Positive & & \\
Negative & 1 & \\
Total & 7 & \\
\hline & & \\
\hline
\end{tabular}


A wide range of congenital anomalies was reported among $\mathrm{FH}$ cases enrolled in this revision. They had a mean limb shortening of $6.06 \pm 2.36 \mathrm{~cm}$ (range from 3 to $11 \mathrm{~cm})$. Knee joint deformities $(87.5 \%)$ and equino valgus deformities of the ankle and foot $(87.5 \%)$ being the most common anomalies associated with $\mathrm{FH}$ cases. Details are shown in Table 3.

Table 3: Details of congenital anomalies associated with fibular hemimelia cases enrolled in the study.

\begin{tabular}{|c|c|c|c|c|c|}
\hline Type of deformity & No. & (\%) & Deformity details & No. & (\%) \\
\hline $\begin{array}{l}\text { Lower limb shortening } \\
(\text { mean }=6.06 \pm 2.36 \mathrm{~cm})\end{array}$ & & & Shortening of tibia & 6 & 75.0 \\
\hline$\leq 5 \mathrm{~cm}$ & 4 & 50.0 & Shortening of femur and tibia & 1 & 12.5 \\
\hline$>5 \mathrm{~cm}$ & 4 & 50.0 & Shortening of femur & 1 & 12.5 \\
\hline Lateral femoral condyle deformity & 5 & 62.5 & Hypoplasia & 5 & 100.0 \\
\hline Inter condylar notch deformity & 1 & 12.5 & Flattening & 1 & 100.0 \\
\hline Knee joint deformity & 7 & 87.5 & Valgus & 7 & 100.0 \\
\hline Patellar deformity & 6 & 75.0 & Hypoplasia & 6 & 100.0 \\
\hline Tibial eminence deformity & 2 & 25.0 & Hypoplasia & 2 & 100.0 \\
\hline \multirow[t]{2}{*}{ Bowing of tibia } & 4 & 50.0 & Antero-medial & 3 & 75.0 \\
\hline & & & Anterior & 1 & 25.0 \\
\hline \multirow[t]{3}{*}{ Equino valgus deformity of ankle } & 7 & 87.5 & Type II & 3 & 42.8 \\
\hline & & & Type IIIA & 2 & 28.6 \\
\hline & & & Type IIIB & 2 & 28.6 \\
\hline \multirow[t]{2}{*}{ Foot deformities } & 6 & 75.0 & Tarsal collision & 3 & 50.0 \\
\hline & & & $\begin{array}{l}\text { Absence of lateral } 2 \text { rays of } \\
\text { foot }\end{array}$ & 3 & 50.0 \\
\hline Upper limb deformities & 1 & 12.5 & - & - & - \\
\hline
\end{tabular}


A number of residual deformities and complications were associated with Ilizarov technique affecting the knee joint, proximal tibia, and ankle joint. Knee joint developed flexion deformity in four cases, valgus deformity in two cases, and posterior sublaxation in one case. While proximal tibia showed bowing deformity (posteromedial and antero-medial) in two cases, residual shortening after primary surgical intervention of up to $3.5 \mathrm{~cm}$ in two cases, and finally residual shortening of up to 2 $\mathrm{cm}$ in two cases. Ankle joint developed valgus deformity in four cases. In addition to these complications, pin tract infection was reported in four cases. Details are shown in Table 4.

Table 4: Residual deformities and complications associated with management of fibular hemimelia cases by llizarov technique.

\begin{tabular}{llll}
\hline Site & Type of residual deformities and complication* & No. & $\%$ \\
\hline Knee joint & Flexion deformity & 4 & 50.0 \\
& Posterior sublaxation & 1 & 12.5 \\
& Valgus deformity & 2 & 23.0 \\
Proximal tibia & Postero medial bowing & 1 & 12.5 \\
& Antero medial bowing & 1 & 12.5 \\
& Residual shortening after primary procedure of up & 2 & 25.0 \\
& to 3.5 cm & & \\
Ankle joint & Residual shortening of up to 2 cm & 2 & 25.0 \\
Pin tract & Valgus deformity & 4 & 50.0 \\
\hline
\end{tabular}

*Subsequent management of residual deformities was as follows:

1. For the flexion deformity of the knee joint, three patients were treated by physiotherapy for fourmonths and improved. One patient underwent soft tissue release.

2. For posterior sublaxation of the knee joint and postero-medial bowing of the tibia which was developed in the same patient, treatment was by re-application of Illizarov according to Graf method. ${ }^{5}$ the postero-medial bowing improved but posterior sublaxation of the knee joint persist due to absence of anterior cruciate ligament. The patient needs anterior cruciate ligament reconstruction in the future.

3. For vulgus deformity of the knee joint supracondylar corrective osteotomy is indicated near maturity.

4. Antero-medial bowing of the tibia was treated by close wedge osteotomy.

5. Those with residual shortening for up to $2 \mathrm{~cm}$ was treated by shoe raise and follow up. Those with up to $3.5 \mathrm{~cm}$ shortening were treated by re-lengthening in successive sessions.

6. Ankle joint deformity type II was treated by supra-malleolar corrective osteotomy. Type IIIA deformity was treated by soft tissue release including elongation of tendenoachellis and posteriorcapsulotomy of ankle joint and supra-malleolar osteotomy. Type IIIB deformity was treated by supra-malleolar osteotomy and sub talar osteotomy to correct valgus deformity of the calcaneum. ${ }^{4}$

7. Pin tract infection was treated by oral and local antibiotics. 
Subsequent surgical management of residual deformities and complications is shown as a footnote to the table. Improvement in LEFS from quite a bit and moderate difficulty to a little bit of difficulty $(P<0.001)$ between the two means of pre and postoperative LEFS is demonstrated (Table 5).

\section{Discussion}

Although llizarov procedure has markedly improved the short-term results and decrease the frequency of complications, ${ }^{8}$ the complication rates of this procedure are stillhigh..$^{6-9} \quad A$ wide spectrum of complications was reported in this study similar to the findings of many other studies conducted worldwide. ${ }^{15-18}$ Catagni et al. ${ }^{19}$ reported knee joint subluxation, flexion contractures, persistent valgus deformity, and pin site infections. Changulaniet al. ${ }^{4}$ reported knee joint stiffness and pin tract infection as complications of limb lengthening in fibular hemimelia. Alaseirlis et al. $^{20}$ reported residual shortening, anterior medial bowing of tibia, and valgus deformity of ankle joint. Rafiq et al. ${ }^{3}$ also reported pin tract infection, knee flexion deformity, knee dislocation, and equinus deformity. In the current study, valgus deformity of the knee joint might be due to already existed hypoplasia of the lateral femoral condyle and anteromedial bowing of the tibia before management with Ilizarov method. ${ }^{21,22}$ On the other hand, the tibial bowing during lengthening procedure might be due to the tethering force of fibrocartilaginous anlage of the fibulafrom the proximal part of the tibia to the posterolateral calcaneus. ${ }^{21,23}$ Severe valgus deformity of the ankle may be correlated with persistent anteromedial bowing of the tibia after lengthening. ${ }^{20,21}$ Improvement of LEFS from quite a bit and moderate difficulty to a little bit of difficulty is similar to that reported by Schep et al. ${ }^{12}$ they reported that LEFS of lower extremity becomes a little bit of difficulty for those who underwent limb lengthening. Alaseirlis et al. $^{20}$ reported that average post-treatment LEFS after 9.7 years follow-up was $89.4 \%$ (ranged from $53 \%$ to $100 \%$ ) compared to average pretreatment LEFS, which was $70.9 \%$ (ranged from $53 \%$ to $96 \%$ ). The retrospective nature of the data and the small sample size of the study are the main limitations of this study.

Table 5: Lower extremity functional scale pre and post Ilizarov technique application.

\begin{tabular}{lcc}
\hline Variable & Preoperative & Postoperative \\
\hline Case 1 & 49 & 77 \\
Case 2 & 43 & 66 \\
Case 3 & 38 & 56 \\
Case 4 & 47 & 73 \\
Case 5 & 32 & 38 \\
Case 6 & 34 & 72 \\
Case 7 & 31 & 65 \\
Case 8 & 34 & 70 \\
Mean \pm SD & & $64.62 \pm 12.48$ \\
$P$ value & $38.5 \pm 6.98$ & \\
\hline
\end{tabular}




\section{Conclusion}

Ilizarov procedure was effective in improving the lower extremity function in fibular hemimelia despite the associated residual deformities and complications and leg length inequality. Further studies with larger samples are needed to support these findings.

\section{Competing interests}

The author declares no competing interests.

\section{References}

1. Paley D. Surgical reconstruction for fibular hemimelia. J Child Orthop 2016; 10(6):557-83.

2. Hamdy RC, Makhdom AM, Saran N, Birch J. Congenital fibular deficiency. J Am Acad Orthop Surg 2014; 22(4):246-55.

3. Rafiq OA, Amen ZJ. Managment of fibular hemimelia (congenital absence of fibula) using llizarov method in Sulaimani. Eur Sci $\mathrm{J}$ 2015; 11:304-16.

4. Changulani M, Ali F, Mulgrew E, Day JB, Zenios M. Outcome of limb lengthening in fibular hemimelia and a functional foot. J Child Orthop 2010; 4(6):519-24.

5. Kulkarni R. Management of fibular hemimelia using llizarov method. In: Kulkarni GS, editor. Textbook of orthopedics and trauma. $2^{\text {nd }}$ ed. New Delhi: Jaypee brothers medical publishers; 2008. P. 1686-91.

6. Shahcheraghi $\mathrm{GH}$, Javid $\mathrm{M}$, Hadavi $\mathrm{F}$. Pediatric lower limbllizarovlengthening with functional evaluation in adulthood: A report onunder privileged patients. J Orthop 2015; 12(Suppl 1):S69-74.

7. Kelly DM. Congenital anomalies of the lower extremity. In: Canale ST, Beaty JH, editors. Campbell's operative orthopaedics. $12^{\text {th }}$ ed. Philadeliphia: Elsevier Mosby; 2013. P. 980-1077.

8. Birch JG, Samchukov ML. Use of the llizarov method to correct lower limb deformities in children and adolescents. J Am Acad Orthop Surg 2004; 12:144-54.

9. Vargas Barreto B, Caton J, Merabet Z, Panisset JC, Pracros JP. Complications of llizarovleg lengthening: a comparative study between patients with leg length discrepancy and short stature. Int Orthop 2007; 31(5):587-91.

10. Jordan C J, Goldstein RY, McLaurin TM, Grant A. The evolution of the llizarov technique. Part1: the history of limb lengthening. Bull Hosp $\mathrm{J}$ Dis 2013; 71(1):89-95.

11. Sabharwal $S$, Rozbruch SR. What's new in limb lengthening and deformity correction? J Bone Joint Surg Am 2011; 93:2323-32.
12. Schep NWL, van Lieshout EMM, Patka $P$, Vogels LMM. Long-term functional and quality of live assessment following post-traumatic distraction osteogenesis of the lower limb. Strategies Trauma Limb Reconstr 2009; 4(3):107 -12 .

13. Binkley JM, Stratford PW, Lott SA, Riddle DL. The lower extremity functional scale (LEFS): scale development, measurement properties, and clinical application. North American Orthopaedic Rehabilitation Research Network. Phys Ther 1999; 79(4):371-83.

14. Paley D, Pfeil J. Principles of deformity correction around the knee. Der Orthopade 2000; 29(1):18-38.

15. Rose R. Tibial lengthening using the classic llizarov technique. The IJOS 2009; 16(1):1-5.

16. Cheng JC, Cheung KW, Ng BK. Severe progressive deformities after limb lengthening in type-II fibular hemimelia. The J Bone Joint Surg $\mathrm{Br}$ 1998; 80(5):772-6.

17. Başbozkurt $M$, Yildiz $C$, Kömürcü $M$, Demiralp $B$, Kürklü $M$, Ateşalp AS. Management of fibular hemimelia with the llizarov circular externalfixator. Acta Orthop Traumatol Turc 2005; 39(1):46-53.

18. Unprasert $\mathrm{P}$, Kaewpornsawan K, Chotigavanichaya C, Eamsobhana P. $\mathrm{M}$ a $\mathrm{n}$ a g e m e $\mathrm{t}$ of $\mathrm{fi}$ bular hemimelia using the llizarov method at Siriraj hospital in Thailand. J Med Assoc Thai 2014; 97 Suppl 9:S44-9.

19. Catagni MA, Radwan M, Lovisetti L, Guerreschi $F$, Elmoghazy NA. Limb lengthening and deformity correction by the llizarov technique in type III fibular hemimelia: an alternative to amputation. Clin Orthop Relat Res 2011; 469(4):1175-80.

20. Alaseirlis DA, Korompilias AV, Beris AE, Soucacos PN. Residual malformations and leg length discrepancy after treatment of fibular hemimelia. J Orthop Surg Res 2011; 6:51.

21. Mishima K, Kitoh H, Iwata K, Matsushita M, Nishida $Y$, Hattori $T$, et al. Clinical results and complications of lower limb lengthening for fibular hemimelia. Medicine 2016; 95(21):e3787.

22. Da Silva RR, Matos MA, Pimentel M, Martins BJ, Oliveira RV. Severe valgus deformity of the knee joint: description of the new surgical technique for its correction. Rev Bras Orto 2012; 47(2):251-6.

23. Mishima K, Kitoh H, Iwata K, Matsushita M, Nishida $Y$, Hattori $T$, et al. Clinical results and complications of lower limb lengthening for fibular hemimelia. Medicine (Baltimore) 2016; 95(21):e3787. 